\title{
Neoadjuvant Therapy of Metformin is Associated with Good Tumor Response After Preoperative Concurrent Chemoradiotherapy for Rectal Cancer
}

Jeonghee Han

Hallym University

Jong Ho kim

Hallym University

Jin-Won Lee

Hallym University

Sang Hyup Han

Hallym University

Hae-sung kim ( $\nabla$ drhjh@hallym.ac.kr)

Hallym University

\section{Research Article}

Keywords: cancer, concurrent chemoradiotherapy (CCRT)

Posted Date: October 20th, 2021

DOI: https://doi.org/10.21203/rs.3.rs-967810/v1

License: (c) (i) This work is licensed under a Creative Commons Attribution 4.0 International License.

Read Full License

Version of Record: A version of this preprint was published at Scientific Reports on March 8th, 2022. See the published version at https://doi.org/10.1038/s41598-022-07768-2. 


\section{Abstract}

Metformin is associated with good tumor response in preoperative concurrent chemoradiotherapy (CCRT) for rectal cancer. This study aims to demonstrate that the timing of metformin is related to the tumor response on preoperative CCRT for rectal cancer. From January 2010 to December 2017, 232 patients who underwent curative resection after preoperative CCRT were reviewed. Patients were divided into groups with or without diabetes or metformin. The timing of metformin administration was divided based on before and after initiation of chemoradiotherapy. Multivariate logistic regression analysis was used to identify predictors for tumor response. Tumor downstaging $(p=0.02)$ and good response rates of tumor regression grade (TRG) $(p=0.008)$ were significantly higher in the group administered metformin before CCRT than other groups. In the multivariate analysis, metformin administration before CCRT was a significant factor in predicting tumor downstaging (odds ratio [OR] 10.31, 95\% confidence interval [CI]: $1.76-102.08, p=0.02)$ and good TRG (OR 12.55, 95\% Cl: $2.38-80.24, p=0.004)$. In patients with rectal cancer who underwent preoperative CCRT, neoadjuvant therapy of metformin before CCRT was significantly associated with good tumor response and tumor downstaging.

\section{Introduction}

Worldwide, the incidence of colorectal cancer is gradually increasing. The third most common disease is colorectal cancer among various carcinomas, and its cancer-specific mortality rate is the fourth ${ }^{1}$. Preoperative concurrent chemoradiotherapy (CCRT) is crucial for the treatment of locally advanced rectal cancer. Thanks to preoperative CCRT for rectal cancer, it is possible to expect the effect of reducing the stage of tumor or lymph nodes and achieving pathological complete response of the tumor ${ }^{2}$. Besides, pathologic complete response ( $\mathrm{pCR}$ ) after CCRT improves postoperative survival ${ }^{3}$. However, the benefit of pCR can only be observed in less than $20 \%$ of patients, and the reason for the difference in tumor response after CCRT is still unknown ${ }^{4}$.

Metformin is a standard treatment for type 2 diabetes mellitus (T2DM), and some studies have reported its effectiveness as an anticancer therapy and anticancer adjuvant for various cancers ${ }^{5,6}$. Several metaanalyses have reported that metformin increases the survival rate of colon cancer ${ }^{6-8}$. Several recent studies show that metformin improves tumor response after preoperative CCRT for rectal cancer. ${ }^{9,10}$. The effect of metformin on increasing the survival rate of rectal cancer is controversial, but the association between metformin and good tumor response after preoperative CCRT is increasingly emerging 9,10.

However, the mechanism of metformin on preoperative CCRT for rectal cancer is not yet definite. There is no study on the timing or dose of metformin for preoperative CCRT. Therefore, this study aims to demonstrate that the timing or dose of metformin administration is related to the tumor response after preoperative CCRT for rectal cancer.

\section{Methods}


Patients. Patients diagnosed with rectal adenocarcinoma between January 2010 and December 2017 were retrospectively reviewed. Patients who underwent CCRT were divided into groups with or without diabetes or metformin. The timing of metformin administration was divided based on before and from the initiation of CCRT (Fig. 1). Compliance with metformin was checked with continuous follow-up by an endocrinologist. The patient's clinical characteristics included the following factors: age, sex, body mass index (BMI), American Society of Anesthesiologists (ASA) score, metformin dose, preoperative carcinoembryonic antigen (CEA), HbA1c, surgical method, tumor histology, and pathology. The rectal tumor was defined as a lesion within $12 \mathrm{~cm}$ from the anal verge. According to the AJCC 7th stage system, the clinical stage cT 3-4 or cN 0-2 without distant metastasis was the target of preoperative CCRT. The clinical stage was evaluated using endoscopy, ultrasonography, contrast-enhanced helical computed tomography (CT), magnetic resonance imaging (MRI), and positron emission tomography (PET)-CT. Patients with a previous history of cancer, familial genetic cancer syndromes, simultaneous cancer in another organ, distant metastasis, drop out of preoperative CCRT, local excision of the tumor, and no available follow-up data were excluded. This study followed the Declaration of Helsinki and was approved by the Internal Research Board of Chun-Cheon Sacred Heart Hospital (approval number: 202105-001). According to the Clinical Ethics Committee of Hallym University College of Medicine, no written consent was required for this retrospective analysis of anonymous data.

Treatment. Patients had treatment with long course radiation therapy for 5 weeks for preoperative CCRT. The whole irradiation dose was 44-54 Gy, and 1.8-2.0 Gy was irradiated per day. Chemotherapy was administered concurrently with radiation therapy, and the regimen was based on 5-FU or capecitabine. 5FU $\left(425 \mathrm{mg} / \mathrm{m}^{2} /\right.$ day $)$ and leucovorin $\left(20 \mathrm{mg} / \mathrm{m}^{2} /\right.$ day $)$ were infused for 5 days in the first and fifth weeks of radiation therapy. Capecitabine $\left(825 \mathrm{mg} / \mathrm{m}^{2} /\right.$ day) was administered orally twice daily during radiotherapy. Curative surgery with total mesorectal excision (TME) was performed about 8 weeks after CCRT.

Tumor response and survival. Rectal MRI was performed before and after radiotherapy, respectively. The size of the tumor and lymph nodes was measured by rectal MRI. The size of the tumor was measured with the longest diameter. For the size of the lymph node, the short axis diameter of the largest lymph node was chosen ${ }^{11}$. After radical surgery, the pathology was confirmed by pathologists. Tumor responses after CCRT were classified according to Mandard grade. The Mandard grade divided the tumor response into 5 categories according to histomorphological regression: grade 1, fibrosis without detectable tumor tissue (pCR); grade 2, fibrosis with scattered tumor cells; grade 3, fibrosis and tumor cells with a preponderance of fibrosis; grade 4, fibrosis and tumor cells with a preponderance of tumor cells; grade 5, tumor tissue without regression-related changes. Tumor response grade (TRG) to CCRT was graded as good (Mandard grade 1,2) or poor (Mandard grade 3-5) ${ }^{12}$. T-downstaging was defined as the difference between the image before CCRT and the pathology of the final T stage ${ }^{13}$. N-downstaging was defined as the reduction between the pre-CCRT imaging results and the final pathological lymph nodes state ${ }^{13}$. Overall survival (OS) was analyzed between groups. OS was defined as the interval between surgery and death or last follow-up. 
Statistical analysis. The primary endpoint was to determine whether TRG was correlated with the timing of metformin administration. The secondary endpoint was to determine the difference in overall survival (OS) rates between groups. The data was expressed as mean \pm standard deviation for continuous variables and mean $\pm 95 \%$ confidence interval $(\mathrm{Cl})$ for categorical variables. The groups were compared regarding clinicopathological factors. Differences between categorical variables were compared using the $\chi^{2}$ test. A one-way analysis of variance (ANOVA) or the Kruskal-Wallis rank-sum test was used to assess continuous variables according to the Shapiro-Wilk normality test. The Kaplan-Meier method was used to estimate OS, and the log-rank test was used for comparison. The associations between tumor responses and clinicopathologic factors were assessed by using logistic regression analysis. Each factor was assessed in a separate univariate logistic regression analysis. Factors that were determined to be significant in univariate analyses were analyzed with multivariate logistic regression, and an odds ratio (OR) and $95 \% \mathrm{Cl}$ were calculated for each factor. P-value lower than 0.05 was considered statistically significant. All statistical analyses were performed using SPSS version 25.0 (IBM Corp., Armonk, NY, USA) after removing patient identifiers from all data sets.

\section{Results}

Patients Characteristics. A total of 232 patients were included, with 176 (75\%) men and 56 women (24\%). There were 156 patients in the non-diabetic group and 76 patients in the diabetic group. In the diabetic group, 32 patients received non-metformin. 30 patients had received metformin before the start of CCRT; administration of metformin was at least 2 weeks before initiation of treatment, and 14 patients received metformin from the initiation of CCRT. There were significant differences in ASA classification between groups $(p=0.02)$. Lower $\mathrm{HbA1C}(5.3 \%, p<0.001)$ was observed in the non-diabetic group. Other clinicopathological features did not show significant differences between groups. Clinicopathological characteristics are summarized in Table 1. The mean dose of metformin was $1159 \mathrm{mg}$ (median: 1000 [250-4000] mg). Non-metformin drugs included insulin, sulfonylureas, thiazolidinediones, an alphaglucosidase inhibitor, or a dipeptidyl peptidase 4 (DPP-4). 
Table 1

Clinicopathologic characteristics. Data are $n(\%)$ or mean \pm SD., Continuous variables expressed as median and interquartile range (IQR 25-75\%). ASA = American Society of Anesthesiologists, VI = vascular invasion, $\mathrm{LI}=$ lymphatic invasion, $\mathrm{CEA}$ = carcinoembrionic antigen, $\mathrm{BMI}=$ body mass index, $\mathrm{CRM}$ = circumferential resection margin. ${ }^{*}$ Low $=$ well or moderately differentiated; High = poorly differentiated

or mucinous carcinoma

\begin{tabular}{|c|c|c|c|c|c|}
\hline & $\begin{array}{l}\text { Non- } \\
\text { diabetic } \\
N=156\end{array}$ & $\begin{array}{l}\text { Non- } \\
\text { Metformin } \\
\mathrm{N}=32\end{array}$ & $\begin{array}{l}\text { Metformin } \\
\text { Before CCRT } \\
\mathrm{N}=30\end{array}$ & $\begin{array}{l}\text { Metformin } \\
\text { From CCRT } \\
\mathrm{N}=14\end{array}$ & $\begin{array}{l}p \\
\text { value }\end{array}$ \\
\hline Sex & & & & & 0.199 \\
\hline Female & $42(26.9 \%)$ & $2(6.2 \%)$ & $6(20.0 \%)$ & $6(42.9 \%)$ & \\
\hline Male & $114(73.1 \%)$ & $30(93.8 \%)$ & $24(80.0 \%)$ & 8 (57.1\%) & \\
\hline Age, y & $62.1 \pm 11.8$ & $61.8 \pm 10.9$ & $64.6 \pm 8.7$ & $69.9 \pm 5.1$ & 0.101 \\
\hline $\mathrm{BMI}, \mathrm{kg} / \mathrm{m}^{2}$ & $\begin{array}{l}23.2 \\
{[21.2 ; 25.0]}\end{array}$ & $\begin{array}{l}23.2 \\
{[20.9 ; 25.9]}\end{array}$ & $23.6[21.9 ; 25.1]$ & $23.7[22.8 ; 28.6]$ & 0.689 \\
\hline $\mathrm{HbA} 1 \mathrm{c}, \%$ & $\begin{array}{l}5.3[5.0 ; \\
5.8]\end{array}$ & $\begin{array}{l}6.8[5.8 \\
7.9]\end{array}$ & $6.7[6.3 ; 7.2]$ & $7.3[6.1 ; 7.5]$ & $<0.001$ \\
\hline $\begin{array}{l}\text { Metformin dose, } \\
\text { mg }\end{array}$ & & & $\begin{array}{l}1000.0 \\
{[625.0 ; 1500.0]}\end{array}$ & $\begin{array}{l}1000.0 \\
{[750.0 ; 1250]}\end{array}$ & $<0.001$ \\
\hline ASA classification & & & & & 0.029 \\
\hline$\square$ & $26(16.7 \%)$ & $0(0.0 \%)$ & $0(0.0 \%)$ & $0(0.0 \%)$ & \\
\hline ૧ & $106(67.9 \%)$ & $22(68.8 \%)$ & $16(53.3 \%)$ & $10(71.4 \%)$ & \\
\hline ૧ & $23(14.7 \%)$ & $10(31.2 \%)$ & $12(40.0 \%)$ & $4(28.6 \%)$ & \\
\hline$\square$ & $1(0.6 \%)$ & $0(0.0 \%)$ & $2(6.7 \%)$ & $0(0.0 \%)$ & \\
\hline $\begin{array}{l}\text { Pre-CCRT CEA, } \\
\mathrm{ng} / \mathrm{ml}\end{array}$ & $\begin{array}{l}2.8[1.9 ; \\
4.1]\end{array}$ & $\begin{array}{l}2.3[1.9 \\
3.8]\end{array}$ & $3.5[2.8 ; 8.4]$ & $2.9[2.0 ; 4.5]$ & 0.435 \\
\hline $\begin{array}{l}\text { Post-CCRT CEA, } \\
\mathrm{ng} / \mathrm{ml}\end{array}$ & $\begin{array}{l}1.8[1.1 ; \\
2.7]\end{array}$ & $\begin{array}{l}1.5[1.2 ; \\
2.0]\end{array}$ & $2.4[1.6 ; 4.0]$ & $2.6[1.5 ; 3.1]$ & 0.239 \\
\hline Tumor location & & & & & 0.310 \\
\hline Lower & $78(50.0 \%)$ & $18(56.2 \%)$ & $8(26.7 \%)$ & $2(14.3 \%)$ & \\
\hline Mid & $35(22.4 \%)$ & $6(18.8 \%)$ & $8(26.7 \%)$ & $6(42.9 \%)$ & \\
\hline Upper & $43(27.6 \%)$ & $8(25.0 \%)$ & $14(46.7 \%)$ & $6(42.9 \%)$ & \\
\hline Operative method & & & & & 0.656 \\
\hline Laparoscopic & $136(87.2 \%)$ & $30(93.8 \%)$ & $22(73.3 \%)$ & $14(100.0 \%)$ & \\
\hline
\end{tabular}




\begin{tabular}{|c|c|c|c|c|c|}
\hline & $\begin{array}{l}\text { Non- } \\
\text { diabetic } \\
\mathrm{N}=156\end{array}$ & $\begin{array}{l}\text { Non- } \\
\text { Metformin } \\
\mathrm{N}=32\end{array}$ & $\begin{array}{l}\text { Metformin } \\
\text { Before CCRT } \\
N=30\end{array}$ & $\begin{array}{l}\text { Metformin } \\
\text { From CCRT } \\
\mathrm{N}=14\end{array}$ & $\begin{array}{l}p \\
\text { value }\end{array}$ \\
\hline Open & $3(1.9 \%)$ & $0(0.0 \%)$ & $0(0.0 \%)$ & $0(0.0 \%)$ & \\
\hline Robot & $17(10.9 \%)$ & $2(6.2 \%)$ & 8 (26.7\%) & $0(0.0 \%)$ & \\
\hline Histologic grade* & & & & & 0.578 \\
\hline High & $10(6.4 \%)$ & 4 (12.5\%) & $4(13.3 \%)$ & $2(14.3 \%)$ & \\
\hline Low & $146(93.6 \%)$ & 28 (87.5\%) & $26(86.7 \%)$ & $12(85.7 \%)$ & \\
\hline VI & & & & & 0.792 \\
\hline Negative & $130(83.3 \%)$ & 28 (87.5\%) & $26(86.7 \%)$ & 10 (71.4\%) & \\
\hline Positive & $26(16.7 \%)$ & 4 (12.5\%) & $4(13.3 \%)$ & $4(28.6 \%)$ & \\
\hline LI & & & & & 0.407 \\
\hline Negative & 131 (84.0\%) & 28 (87.5\%) & $30(100.0 \%)$ & $12(85.7 \%)$ & \\
\hline Positive & $25(16.0 \%)$ & $4(12.5 \%)$ & $0(0.0 \%)$ & $2(14.3 \%)$ & \\
\hline CRM & & & & & 0.433 \\
\hline Negative & 154 (98.7\%) & 30 (93.8\%) & $30(100.0 \%)$ & $14(100.0 \%)$ & \\
\hline Positive & $2(1.3 \%)$ & $2(6.2 \%)$ & $0(0.0 \%)$ & $0(0.0 \%)$ & \\
\hline
\end{tabular}

Timing of metformin and tumor response. Tumor responses among the 4 groups: T-downstaging, $\mathrm{N}$ downstaging, TRG, and pCR were evaluated through histopathology after surgery. There were no significant differences in clinical $\mathrm{T}$ and $\mathrm{N}$ stages, and postoperative ypT and ypN stages among the four groups. There was no significant difference between the 4 groups in N-downstaging. However, the rate of T-downstaging was significantly higher in the group administered metformin before the initiation of CCRT $(80.0 \%, p<0.02)$. In addition, the good response rate of TRG was also observed significantly higher in the group administered metformin before the initiation of CCRT $(66.7 \%, p<0.008)$. Tumor responses of the groups are described in Table 2. Especially, the rate of T-downstaging and the good response of TRG was significantly higher in the group receiving metformin before the initiation of CCRT than in the non-diabetic group (Fig. 2). 
Table 2

Tumor response by groups. Data are $\mathrm{n}(\%), \mathrm{TRG}=$ tumor regression grade, $\mathrm{pCR}=$ pathologic complete response, $\mathrm{cT}^{*}=$ Clinical Tumor stage; ypT $+=$ Pathological tumor stage; $\mathrm{cN} \neq=$ Clinical Node stage; $\mathrm{ypN}^{\star} \dagger=$ = Pathological Node stage; $\mathrm{TRG}^{\star}+\S=$ Mandard grade (1-2; good, 3-5; poor).

\begin{tabular}{|c|c|c|c|c|c|}
\hline & $\begin{array}{l}\text { Non- } \\
\text { diabetic } \\
\mathrm{N}=156\end{array}$ & $\begin{array}{l}\text { Non- } \\
\text { Metformin } \\
\mathrm{N}=32\end{array}$ & $\begin{array}{l}\text { Metformin } \\
\text { Before CCRT } \\
\mathrm{N}=30\end{array}$ & $\begin{array}{l}\text { Metformin } \\
\text { From CCRT } \\
\mathrm{N}=14\end{array}$ & $p$ value \\
\hline$c T^{*}$ & & & & & 0.047 \\
\hline 3 & $153(98.1 \%)$ & $30(93.8 \%)$ & $26(86.7 \%)$ & 12 (85.7\%) & \\
\hline 4 & $3(1.9 \%)$ & $2(6.2 \%)$ & $4(13.3 \%)$ & $2(14.3 \%)$ & \\
\hline урт† & & & & & 0.405 \\
\hline 0 & $20(12.8 \%)$ & $6(18.8 \%)$ & 10 (33.3\%) & $0(0.0 \%)$ & \\
\hline 1 & 9 (5.8\%) & $4(12.5 \%)$ & $2(6.7 \%)$ & $4(28.6 \%)$ & \\
\hline 2 & $32(20.5 \%)$ & $6(18.8 \%)$ & $10(33.3 \%)$ & $0(0.0 \%)$ & \\
\hline 3 & $94(60.3 \%)$ & $8(50.0 \%)$ & 8 (26.7\%) & 10 (71.4\%) & \\
\hline $4 a$ & $1(0.6 \%)$ & $0(0.0 \%)$ & $0(0.0 \%)$ & $0(0.0 \%)$ & \\
\hline $\mathrm{cN} \ddagger$ & & & & & 0.987 \\
\hline 0 & $65(41.7 \%)$ & $16(50.0 \%)$ & $12(40.0 \%)$ & $6(42.9 \%)$ & \\
\hline 1 & $22(14.1 \%)$ & $2(6.2 \%)$ & $4(13.3 \%)$ & $2(14.3 \%)$ & \\
\hline 2 & $69(44.2 \%)$ & $14(43.8 \%)$ & $14(46.7 \%)$ & $6(42.9 \%)$ & \\
\hline $\mathrm{ypN}^{*}+$ & & & & & 0.757 \\
\hline 0 & $112(71.8 \%)$ & $22(68.8 \%)$ & $22(73.3 \%)$ & $12(85.7 \%)$ & \\
\hline $1 a$ & 15 (9.6\%) & $6(18.8 \%)$ & 2 (6.7\%) & $0(0.0 \%)$ & \\
\hline $1 b$ & 12 (7.7\%) & $4(12.5 \%)$ & 2 (6.7\%) & $0(0.0 \%)$ & \\
\hline $1 c$ & $3(1.9 \%)$ & $0(0.0 \%)$ & $0(0.0 \%)$ & $0(0.0 \%)$ & \\
\hline $2 a$ & 13 (8.3\%) & $0(0.0 \%)$ & $2(6.7 \%)$ & $2(14.3 \%)$ & \\
\hline $2 b$ & $1(0.6 \%)$ & $0(0.0 \%)$ & $2(6.7 \%)$ & $0(0.0 \%)$ & \\
\hline TRG*†§ & & & & & 0.008 \\
\hline Poor & 115 (73.7\%) & $20(62.5 \%)$ & $10(33.3 \%)$ & $12(85.7 \%)$ & \\
\hline Good & $41(26.3 \%)$ & $12(37.5 \%)$ & $20(66.7 \%)$ & $2(14.3 \%)$ & \\
\hline
\end{tabular}




\begin{tabular}{|llllll|}
\hline & $\begin{array}{l}\text { Non- } \\
\text { diabetic } \\
\text { N=156 }\end{array}$ & $\begin{array}{l}\text { Non- } \\
\text { Metformin }\end{array}$ & $\begin{array}{l}\text { Metformin } \\
\text { Before CCRT } \\
\text { N=30 }\end{array}$ & $\begin{array}{l}\text { Metformin } \\
\text { From CCRT }\end{array}$ & N value \\
\hline pCR & & & & & 0.107 \\
\hline No & $136(87.2 \%)$ & $26(81.2 \%)$ & $20(66.7 \%)$ & $14(100.0 \%)$ & \\
\hline Yes & $20(12.8 \%)$ & $6(18.8 \%)$ & $10(33.3 \%)$ & $0(0.0 \%)$ & 0.022 \\
\hline T downstaging & & & & & \\
\hline No & $93(59.6 \%)$ & $14(43.8 \%)$ & $6(20.0 \%)$ & $8(57.1 \%)$ & \\
\hline Yes & $63(40.4 \%)$ & $18(56.2 \%)$ & $24(80.0 \%)$ & $6(42.9 \%)$ & \\
\hline N downstaging & & & & & \\
\hline No & $84(53.8 \%)$ & $16(50.0 \%)$ & $18(60.0 \%)$ & $8(57.1 \%)$ & \\
\hline Yes & $72(46.2 \%)$ & $16(50.0 \%)$ & $12(40.0 \%)$ & $6(42.9 \%)$ & \\
\hline
\end{tabular}

Univariate and multivariate analyses of logistic regression models were performed to identify the factors predicting the tumor responses. There was no difference in tumor response between 5-FU and capecitabine chemotherapy $(p=0.2)$. Furthermore, there was no statistical difference in T-downstaging ( $p$ $=0.2)$, N-downstaging $(p=0.8), \operatorname{pCR}(p=0.3)$, and tumor response $(p=0.2)$ according to the dose of metformin. In univariate logistic regression analysis; $\mathrm{HbA1c}$, vascular invasion $(\mathrm{VI})$, ypT, and cN were significant factors for predicting pCR; $\mathrm{CT}, \mathrm{cN}$, and ypT were independent factors related to $\mathrm{N}$-downstaging; Metformin administration before the initiation of CCRT, low histological grade, VI, lymphatic invasion (LI), $\mathrm{cT}, \mathrm{cN}$, and ypN were independent factors associated with T-downstaging; Metformin administration before the initiation of CCRT, VI, LI, cN, ypT, T-downstaging, and N-downstaging were significant factors for predicting good TRG. Multivariate analysis was performed with predictors $(p<0.01)$ related to the tumor response in the univariate analysis (Table 3). Metformin administration before the initiation of CCRT was a significant factor in predicting T-downstaging (OR 10.31,95\% Cl: $1.76-102.08, p=0.02$ ) and good response of TRG (OR 12.55, 95\% Cl: $2.38-80.24, p=0.004)$. 
Table 3

Multivariable logistic regression analysis for tumor response. $\mathrm{VI}=$ vascular invasion, $\mathrm{LI}=$ lymphatic invasion, $\mathrm{CEA}=$ carcinoembrionic antigen, $\mathrm{TRG}=$ tumor regression grade, $\mathrm{Cl}=$ confidence interval.

\begin{tabular}{|c|c|c|c|c|}
\hline Variables & OR & \multicolumn{2}{|c|}{$95 \% \mathrm{Cl}$} & $p$ value \\
\hline \multicolumn{5}{|l|}{ T downstaging } \\
\hline Neoadjuvant metformin & 10.31 & 1.76 & 102.08 & 0.02 \\
\hline Preoperative CEA & 0.96 & 0.89 & 1.02 & 0.23 \\
\hline Histologic grade & 15.78 & 2.52 & 34.167 & 0.01 \\
\hline VI & 0.48 & 0.1 & 2.02 & 0.32 \\
\hline LI & 0.44 & 0.08 & 2.3 & 0.33 \\
\hline cT & 24.53 & 1.43 & 17.875 & 0.08 \\
\hline $\mathrm{cN}$ & 0.88 & 0.61 & 1.29 & 0.51 \\
\hline \multicolumn{5}{|l|}{ N downstaging } \\
\hline Age & 1.03 & 0.98 & 1.07 & 0.27 \\
\hline cT & 1.84 & 0.19 & 4.977 & 0.65 \\
\hline урт & 0.73 & 0.31 & 1.69 & 0.45 \\
\hline $\mathrm{cN}$ & 17.71 & 9.22 & 39.36 & $\nabla 0.001$ \\
\hline pCR & 0.66 & 0.06 & 7.86 & 0.73 \\
\hline \multicolumn{5}{|l|}{$p C R$} \\
\hline Age & 0.96 & 0.71 & 1.17 & 0.72 \\
\hline $\mathrm{HbA1c}$ & 20.22 & 2.29 & 3.26 & 0.07 \\
\hline Preoperative CEA & 0.64 & 0.23 & 1.32 & 0.26 \\
\hline Location of tumor & 1.74 & 0.3 & 30.65 & 0.60 \\
\hline VI & 0.3 & 0.01 & 8.353 & 0.77 \\
\hline урт & 0.1 & 0.002 & 0.02 & 0.01 \\
\hline $\mathrm{cN}$ & 0.2 & 0.01 & 1.31 & 0.15 \\
\hline \multicolumn{5}{|l|}{$T R G$} \\
\hline Age & 0.99 & 0.95 & 1.03 & 0.61 \\
\hline Neoadjuvant metformin & 12.55 & 2.38 & 80.24 & 0.004 \\
\hline Preoperative CEA & 1.02 & 0.92 & 1.1 & 0.70 \\
\hline
\end{tabular}




\begin{tabular}{|c|c|c|c|c|}
\hline Variables & OR & \multicolumn{2}{|c|}{$95 \% \mathrm{Cl}$} & $p$ value \\
\hline VI & 0.35 & 0.03 & 2.75 & 0.36 \\
\hline LI & 0.41 & 0.02 & 4.26 & 0.50 \\
\hline урт & 0.09 & 0.03 & 0.21 & $\varangle 0.001$ \\
\hline $\mathrm{cN}$ & 1.27 & 0.35 & 4.74 & 0.71 \\
\hline
\end{tabular}

Survival Analysis. The follow-up period for survival was at least 4 years. In the survival analysis, there was no significant difference in the overall survival between the 4 groups. There was no difference in the overall survival rate for the timing of metformin administration for CCRT. There was a trend of increased survival rate in the good TRG group, but there was no statistically significant difference in the survival rate between good and poor TRG (Fig. 3). Because the total number of events was insufficient, the cox proportional hazards model for survival factors analysis could not be performed.

\section{Discussion}

Preoperative CCRT for rectal cancer is an important treatment for inducing good tumor response and ultimately achieving PCR. However, 5-FU based chemotherapy can cause side effects related to toxicity. Several randomized control trials (RCTs) have demonstrated that the chemo-related toxicity increases in patients receiving preoperative CCRT rather than single radiation therapy in the preoperative treatment setting for rectal cancer ${ }^{14-16}$. If a patient fails to achieve an adequate tumor response due to chemorelated toxicity, the patient's prognosis may be poor. Therefore, studies to find alternatives or adjuvants that can reduce chemo-related toxicity and induce better tumor response are attracting attention.

Some studies have reported the effectiveness of metformin as an anticancer therapy and anticancer adjuvant for various cancers ${ }^{5,6}$. Several recent studies show that metformin improves tumor response after preoperative CCRT for rectal cancer ${ }^{9,10}$. Retrospective studies have suggested that metformin use is associated with $\mathrm{N}$-downstaging, pCR, and good TRG 9,10,17. Several researchers have conducted studies on metformin, but there are no clinical studies on the timing and dose of metformin for tumor response of preoperative CCRT. This study proved that the timing of metformin administration for CCRT was related to the tumor response. Indeed, a study has shown that the formation of aberrant crypt foci (ACF) in the rectum is inhibited in patients receiving metformin for 1 month ${ }^{18}$. Additionally, Zhao et al. reported that when metformin was administered at $1500 \mathrm{mg} /$ day, the number of ACFs significantly reduced in the patient group taking metformin for 6 months compared to when metformin was administered for 3 months ${ }^{19}$. In our study, patients who took metformin before the initiation of CCRT showed better tumor response than those who took metformin from the initiation of CCRT. In several studies, the rate of stage reduction due to metformin was $45-70 \% 9,10$. In our study, the rates of T-downstaging, N-downstaging, and good TRG in the underlying metformin usage group were higher than in the other groups $(80 \%, 40 \%$, $66.7 \%$, respectively). In particular, the rates of T-downstaging and good TRG increased significantly in the 
underlying metformin usage group ( $p=0.02, p=0.008$, respectively). In other studies, the pCR rate was $20-25 \% 9,10$, but in this study, the pCR rate of $33.3 \%$ was observed in patients who took metformin before the initiation of CCRT. In a multivariate analysis to identify predictors of tumor responses, metformin administration before the initiation of CCRT was found to be a significant predictor for predicting Tdownstaging and good TRG. These results suggest that neoadjuvant metformin administration can have an intensive effect in addition to CRT.

The importance of the Akt phosphorylation and consequent activation in conferring resistance to radiation therapy has been shown, which explains the molecular mechanisms that determine poor response to radiation therapy ${ }^{20}$. Metformin interferes with the mitochondrial respiratory complex 1 and decreases the effectiveness of intracellular ATP. Reduction of ATP indirectly increases the activity of AMPK, an inhibitor of the PI3K/Akt/mTOR pathway, resulting in an overall decrease in the mTOR pathway 21,22 . In the cell line treated with metformin for more than 24 hours, AMPK was significantly increased, but within 2 hours, AMPK was not increased ${ }^{23}$. In addition, phosphorylation of Akt did not decrease at 2 hours after metformin treatment, but it was removed after 24 hours ${ }^{23}$. Treatment with metformin inhibits the PI3K/Akt/mTOR pathway, inhibiting protein synthesis and cell growth, resulting in anticancer activity. The above results may suggest that the timing of metformin administration affects the treatment response, as shown in our study.

One study shows that metformin increases survival rates in patients with colorectal cancer ${ }^{9}$. However, in the ECR-PHARMO cohort, it was reported that the benefit of overall survival in colorectal cancer was not associated with metformin ${ }^{24}$. Although this study showed a trend of increased survival rate in the good TRG group, it is likely that the patient's overall sample size and death events were not enough to derive significant results.

There are several limitations to this study. First, there are limitations of retrospective studies and small sample sizes. Second, since preoperative staging was based on imaging studies, it is inevitable to limit the accuracy of tumor response. However, to our knowledge, this study is the first clinical study on the neoadjuvant effect of metformin for tumor response of preoperative CCRT. A synergistic effect between the neoadjuvant metformin and CCRT can be expected based on this study. In addition, the potential effects of neoadjuvant metformin may affect the choice of a short course or long course radiation therapy. In the future, long-term, large-scale, well-designed randomized controlled trials are needed in the setting of patients with the adjustment for detailed relevant clinical and molecular factors.

In conclusion, in patients with rectal cancer who underwent preoperative CCRT and curative surgery, underlying metformin usage was significantly associated with good tumor response and tumor downstaging. This study suggests that neoadjuvant metformin improves response to radiation therapy in patients with rectal cancer. This study is of value in developing therapeutic strategies to improve tumor response in patients with rectal cancer.

\section{Declarations}




\section{Data availability}

Data are available from the authors upon reasonable request and with permission.

\section{Author contributions}

$\mathrm{JH}$ wrote and drafted the manuscript; contributed to the conception, design, analysis, and interpretation of data; provided criticism. JHK contributed to patient supply and follow-up data collection; provided criticism and critical revision of the manuscript. JWL and SHH contributed to the design, analysis, and interpretation of data; provided criticism of the manuscript. HK drafted the manuscript; contributed to conception, patient supply, database maintenance, and follow-up data collection; provided criticism. All authors read and approved the final version to be published.

\section{Competing interests}

The authors declare no competing interests.

\section{Additional information}

Correspondence and requests for materials should be addressed to H.K.

Reprints and permissions information is available at www.nature.com/reprints.

Publisher's note Springer Nature remains neutral with regard to jurisdictional claims in published maps and institutional affiliations.

\section{References}

1. Wiseman, M. \& The second World Cancer Research Fund/American Institute for Cancer Research expert report. Food, nutrition, physical activity, and the prevention of cancer: a global perspective. Proc Nutr Soc, 67, 253-256 https://doi.org/10.1017/s002966510800712x (2008).

2. Sauer, R. et al. Preoperative versus postoperative chemoradiotherapy for rectal cancer. N Engl J Med, 351, 1731-1740 https://doi.org/10.1056/NEJMoa040694 (2004).

3. Maas, M. et al. Long-term outcome in patients with a pathological complete response after chemoradiation for rectal cancer: a pooled analysis of individual patient data. Lancet Oncol, 11, 835-844 https://doi.org/10.1016/s1470-2045(10)70172-8 (2010).

4. Gash, K. J., Chambers, A. C., Cotton, D. E., Williams, A. C. \& Thomas, M. G. Potentiating the effects of radiotherapy in rectal cancer: the role of aspirin, statins and metformin as adjuncts to therapy. $\mathrm{Br} J$ Cancer, 117, 210-219 https://doi.org/10.1038/bjc.2017.175 (2017).

5. Zannella, V. E. et al. Reprogramming metabolism with metformin improves tumor oxygenation and radiotherapy response. Clin Cancer Res, 19, 6741-6750 https://doi.org/10.1158/1078-0432.Ccr-131787 (2013). 
6. Zhang, Z. J. et al. Reduced risk of colorectal cancer with metformin therapy in patients with type 2 diabetes: a meta-analysis., 34, 2323-2328 https://doi.org/10.2337/dc11-0512 (2011).

7. Landman, G. W. et al. Metformin associated with lower cancer mortality in type 2 diabetes: ZODIAC16., 33, 322-326 https://doi.org/10.2337/dc09-1380 (2010).

8. Mei, Z. B. et al. Survival benefits of metformin for colorectal cancer patients with diabetes: a systematic review and meta-analysis. PLoS One, 9, e91818 https://doi.org/10.1371/journal.pone.0091818 (2014).

9. Kim, J. M. et al. Survival Benefit for Metformin Through Better Tumor Response by Neoadjuvant Concurrent Chemoradiotherapy in Rectal Cancer. Dis Colon Rectum, 63, 758-768 https://doi.org/10.1097/dcr.0000000000001624 (2020).

10. Oh, B. Y. et al. Metformin enhances the response to radiotherapy in diabetic patients with rectal cancer. J Cancer Res Clin Oncol, 142, 1377-1385 https://doi.org/10.1007/s00432-016-2148-x (2016).

11. Essential Items for Structured Reporting of Rectal Cancer MRI. 2016 Consensus Recommendation from the Korean Society of Abdominal Radiology. Korean J Radiol, 18, 132-151 https://doi.org/10.3348/kjr.2017.18.1.132 (2017).

12. Siddiqui, M. R. et al. Defining response to radiotherapy in rectal cancer using magnetic resonance imaging and histopathological scales. World J Gastroenterol, 22, 8414-8434 https://doi.org/10.3748/wjg.v22.i37.8414 (2016).

13. Kim, D. J. et al. Restaging of Rectal Cancer with MR Imaging after Concurrent Chemotherapy and Radiation Therapy., 30, 503-516 https://doi.org/10.1148/rg.302095046 (2010).

14. Bujko, K. et al. Long-term results of a randomized trial comparing preoperative short-course radiotherapy with preoperative conventionally fractionated chemoradiation for rectal cancer. $\mathrm{Br} J$ Surg, 93, 1215-1223 https://doi.org/10.1002/bjs.5506 (2006).

15. Ansari, N. et al. Acute Adverse Events and Postoperative Complications in a Randomized Trial of Preoperative Short-course Radiotherapy Versus Long-course Chemoradiotherapy for T3 Adenocarcinoma of the Rectum: Trans-Tasman Radiation Oncology Group Trial (TROG 01.04). Ann Surg, 265, 882-888 https://doi.org/10.1097/sla.0000000000001987 (2017).

16. Ngan, S. Y. et al. Randomized trial of short-course radiotherapy versus long-course chemoradiation comparing rates of local recurrence in patients with $\mathrm{T} 3$ rectal cancer: Trans-Tasman Radiation Oncology Group trial 01.04. J Clin Oncol, 30, 3827-3833 https://doi.org/10.1200/jco.2012.42.9597 (2012).

17. Skinner, H. D. et al. Metformin use and improved response to therapy in rectal cancer. Cancer Med, 2 , 99-107 https://doi.org/10.1002/cam4.54 (2013).

18. Higurashi, T. et al. The efficacy of aspirin and metformin combination therapy in patients with rectal aberrant crypt foci: a double-blinded randomized controlled trial. BMC Cancer, 20, 1043 https://doi.org/10.1186/s12885-020-07564-z (2020). 
19. Zhao, X. et al. Effects of different doses of metformin treatment for 6 months on aberrant crypt foci in Chinese patients with impaired glucose tolerance. Eur J Cancer Prev, 24, 27-36 https://doi.org/10.1097/cej.0000000000000078 (2015).

20. Koyama, F. C. et al. Effect of Akt activation and experimental pharmacological inhibition on responses to neoadjuvant chemoradiotherapy in rectal cancer. Br J Surg, 105, e192-e203 https://doi.org/10.1002/bjs.10695 (2018).

21. Koritzinsky, M. \& Metformin A Novel Biological Modifier of Tumor Response to Radiation Therapy. Int J Radiat Oncol Biol Phys, 93, 454-464 https://doi.org/10.1016/j.jijrobp.2015.06.003 (2015).

22. Viollet, B. et al. Cellular and molecular mechanisms of metformin: an overview. Clin Sci (Lond), 122, 253-270 https://doi.org/10.1042/cs20110386 (2012).

23. Fernandes, J. M. et al. Metformin as an Alternative Radiosensitizing Agent to 5-Fluorouracil During Neoadjuvant Treatment for Rectal Cancer. Dis Colon Rectum, 63, 918-926 https://doi.org/10.1097/dcr.0000000000001626 (2020).

24. Zanders, M. M. et al. Are metformin, statin and aspirin use still associated with overall mortality among colorectal cancer patients with diabetes if adjusted for one another? Br J Cancer, 113, $403-$ 410 https://doi.org/10.1038/bjc.2015.259 (2015).

\section{Figures}

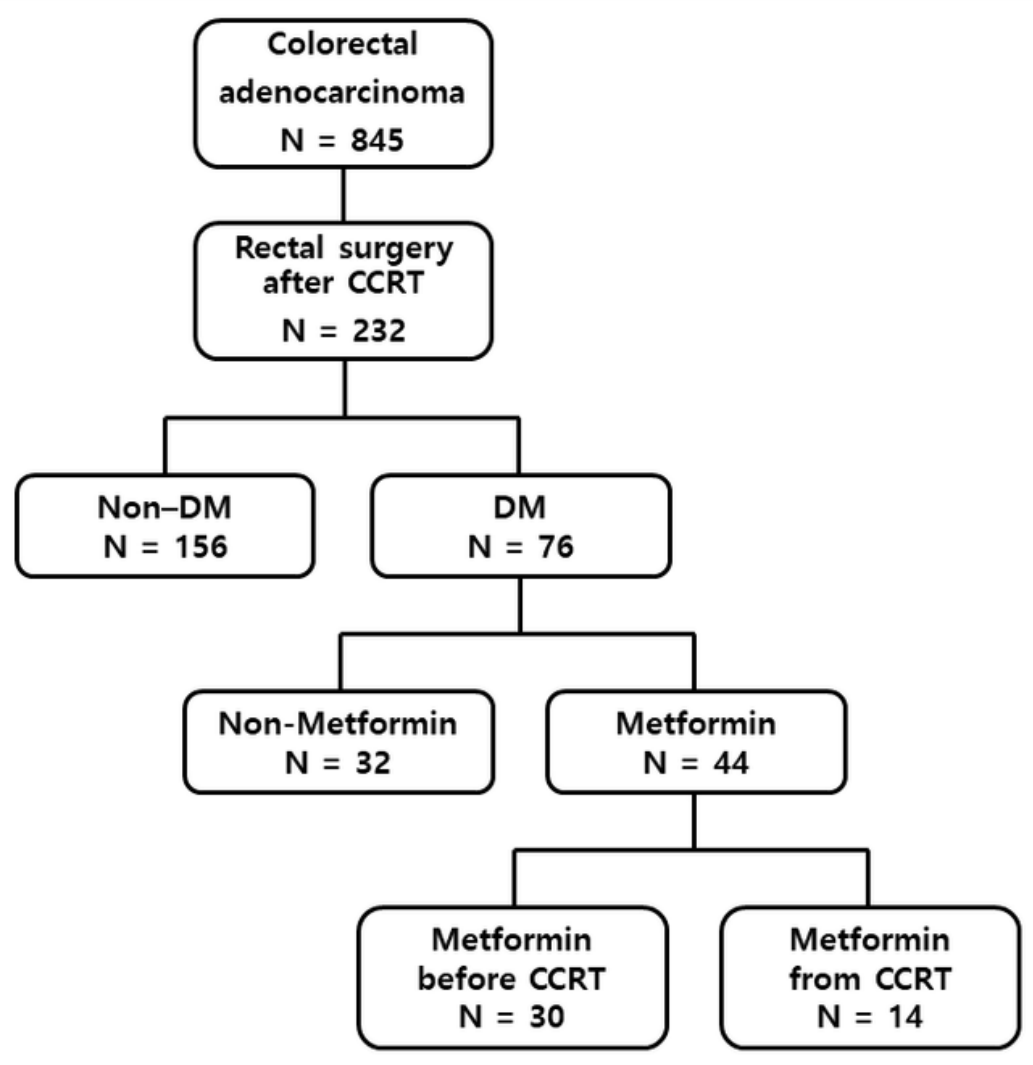

Figure 1 
Flow chart of patient group.
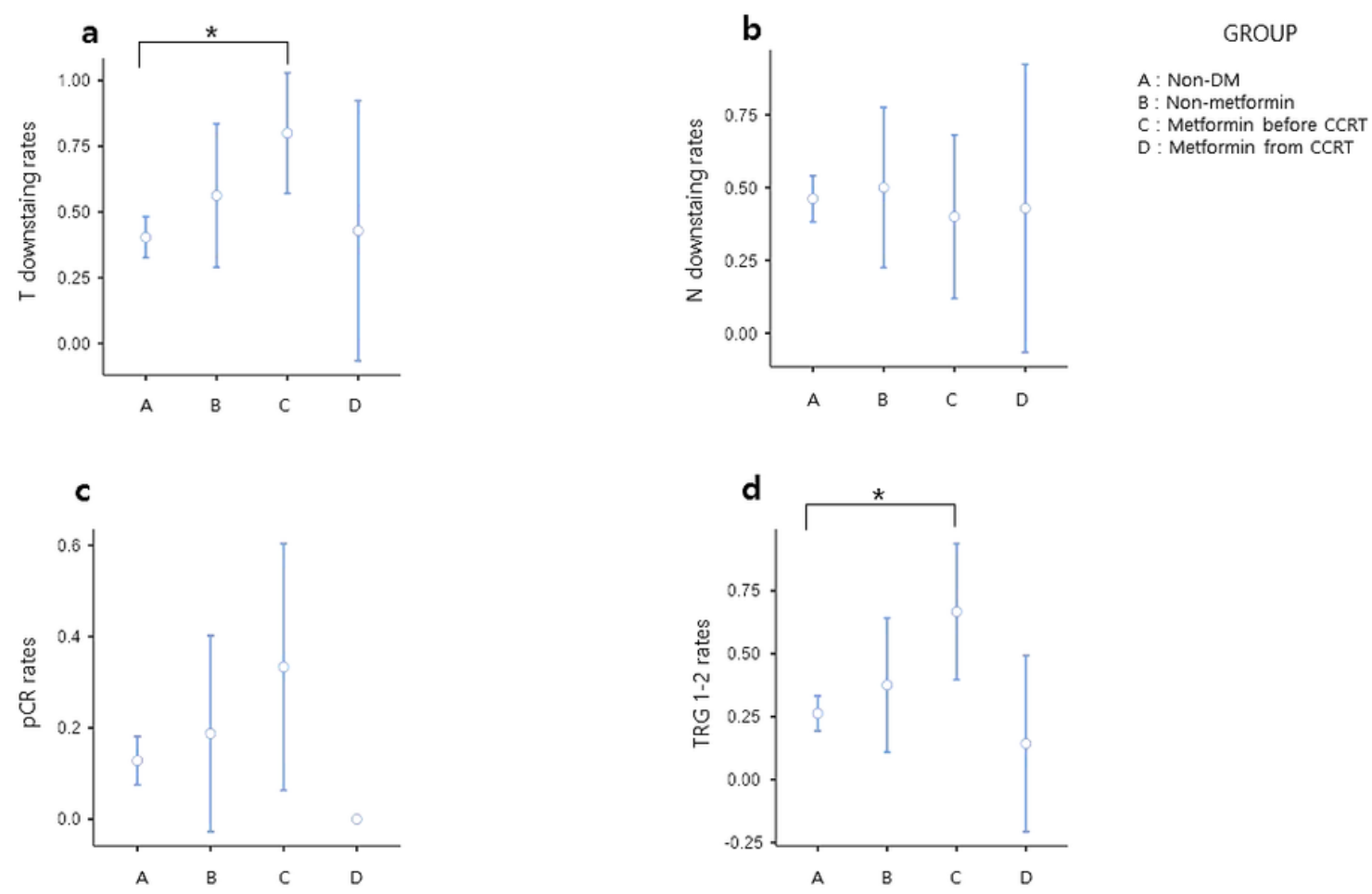

\section{Figure 2}

Tumor response rates between groups. a T downstaging, $\mathrm{b} \mathrm{N}$ downstaging, $\mathrm{c}$ pathologic complete response, $d$ tumor regression grade, $* p<0.005$ 


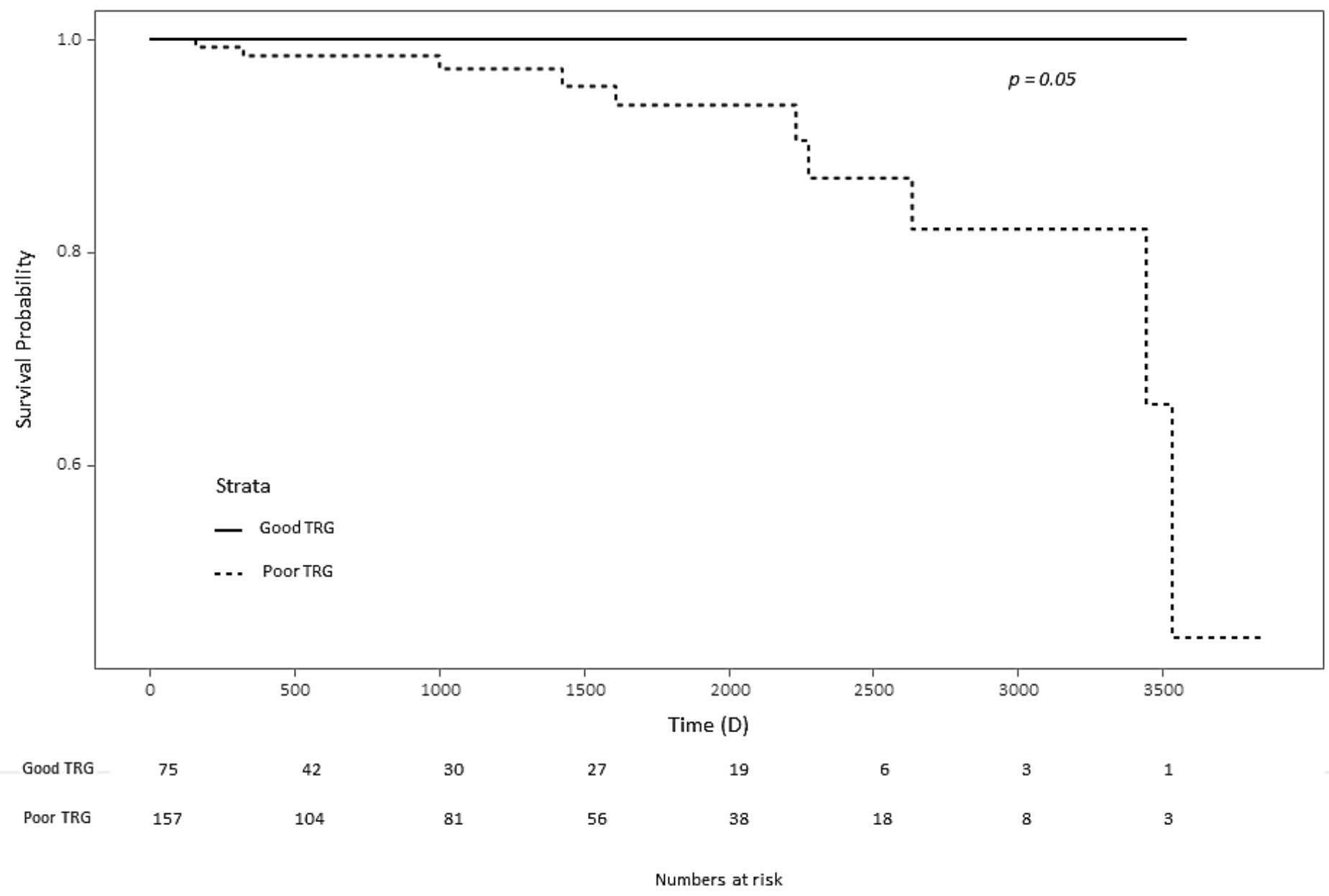

\section{Figure 3}

The Kaplan-Meier curve for overall survival according to tumor regression grade. 